\title{
Más allá de la contienda: representaciones del soldado anónimo en la obra de Romain Rolland
}

\author{
Above the Battle: Representations of the anonymous soldier in Romain \\ Rolland's work
}

\section{Núria Molines Galarza}

Universitat Jaume I de Castelló.nmolines@uji.es

Recibido: 23.06.2019. Aceptado: 26.07.2019

Resumen: Comprometido con el pacifismo y el ideal humanista, para Romain Rolland, la Primera Guerra Mundial supuso una debacle personal y autoral al verse prácticamente solo en una Europa donde los "regimientos de la pluma" se dedicaron a orquestar el odio de los pueblos. Rolland, en cambio, colaboró con la Agencia Internacional de Prisioneros de Guerra en Suiza, país donde permaneció en una suerte de exilio hasta el final del conflicto. Así accede a los testimonios de soldados de ambos bandos, que luego reflejará en sus artículos, publicados en el volumen Au-dessus de la mêlée (1915), en sus diarios, correspondencia con autores como Stefan Zweig, y en la obra con la que culmina este aciago periodo: Clerambault (1920).

Palabras clave: Romain Rolland; Primera Guerra Mundial; soldado; Clerambault; Más allá de la contienda.

\begin{abstract}
Committed to pacifism and humanism, Romain Rolland lives with the First World War a personal and authorial debacle, seeing himself practically alone in a Europe where the "regiments of the pen" were orchestrating the hatred between the peoples. Instead, Rolland collaborated with the International Prisoners-of-War Agency in Switzerland, where he lived in a sort of exile until the end of the conflict. Hence, there he gains access to soldier's testimonies from both sides, which he will later reflect in his articles, published in the volume Au-dessus de la mêlée (1915), in his diaries, correspondence with authors such as Stefan Zweig, and in the work that culminates this fateful period: Clerambault (1920).
\end{abstract}

Keywords: Romain Rolland; First World War; soldier; Clerambault; Más allá de la contienda.

》) Molines Galarza, Núria. 2019. "Más allá de la contienda: representaciones del soldado anónimo en la obra de Romain Rolland". Quaderns de Filologia: Estudis Literaris XXIV: 153-167. doi: 10.7203/qdfed.24.16337 



\section{La Gran Guerra y Romain Rolland: la pluma, la contienda y el compromiso con la paz}

En la biografía que dedicó a su maestro Romain Rolland, Stefan Zweig alude a los cañonazos de aquel largo verano de 1914 como momento clave en el que todos los ideales humanistas, de fraternidad y unión europea, se van al traste. El sueño de la razón produjo grandes monstruos, apenas atisbados años antes: el nacionalismo, la reacción o el belicismo. La intelectualidad, esos "ejércitos de la pluma", en vez de lanzarse a detener con sus medios - la palabra, el razonamiento-aquella barbarie, cargaron las tintas y rompieron los puentes que hasta hacía poco se extendían entre las naciones. La idea de la Europa fraterna se hace añicos:

El 2 de agosto de 1914 desgarró a Europa en dos pedazos [...]. Pletóricos de odio, los corsarios de la guerra enterraron en todas partes, con golpes de azada furiosos, la otrora sagrada idea de la fraternidad humana, como un cadáver junto a millones de muertos (Zweig 1942: 166).

Para entender el papel que desempeña en la obra rollandiana la Gran Guerra y, en especial, en sus representaciones del soldado anónimo, primero es preciso detenerse a contextualizar la posición del autor en aquella época. En primer lugar, podríamos decir que Rolland se encuentra, antes del inicio del conflicto, en uno de los momentos álgidos de su carrera -aunque el culmen llegará con el Nobel de Literatura que le concederán en 1915-. Ha publicado ya sus grandes biografías, La Vie de Beethoven (1903), La Vie de Michel-Ange (1906) y La Vie de Tolstoï (1911) - de tres grandes europeos en el sentido más amplio del término, y ninguno francés, cabe destacar-, y, sobre todo, ha puesto punto final a su gran obra europea, el legado que recibirá toda una generación, Jean-Christophe (1904-1912). Esa obra, que se publicó por entregas a lo largo de doce años, desde L'Aube et le Matin (escrita de julio a octubre de 1903) a La Nouvelle Journée (escrita desde finales de julio de 1911 a junio de 1912) (Rolland, 2007: 12) viene encabezada por un lema que guiará gran parte de su obra no solo en ese momento previo al conflicto, sino también después, y aún con más firmeza: "Aux âmes libres de toutes les nations qui souffrent, qui luttent, et qui vaincront" (ibíd.: 7). Esa firme convicción será lo que permita a Rolland escribir pese a todo y pese a todos en los aciagos años que vendrían por delante. 
El 31 de julio de 1914 empieza el Journal des années de guerre de Rolland, un monumental diario que llega hasta 1919 y nos permite seguir, prácticamente al día, todos los acontecimientos relacionados con la Gran Guerra, tanto políticos como sociales, intelectuales y propios del autor. En ese último día de julio, Rolland (1970: 31) nos cuenta que, ante un precioso paisaje veraniego, de cielos despejados, con el aroma de las glicinas impregnando la noche, da comienzo la "gran matanza". Justo al día siguiente se produce el asesinato de Jaurès, hecho que, como veremos más tarde, da inicio a la acción narrativa de su novela del periodo bélico, Clerambault. En esos días, Rolland no se encuentra en Francia, sino en Suiza. Aunque no es algo que él eligiese, ya que se encuentra allí de manera algo casual, pasando el verano en el país helvético como ya había hecho en otras muchas ocasiones desde que lo descubrió en 1882 (Juin, 2012: 4); tras llegar a Suiza a principios de junio, se dedica a terminar su manuscrito de Colas Brugnon-obra que no se publicará hasta después de la guerra-. Por tanto, cabe incidir en que, si bien Rolland decide no volver a Francia durante el conflicto, no sería acertado decir que huyó al país vecino o que se exilió allí al estallar la guerra. A su vez, a sus cuarenta y ocho años, y dada su frágil salud (ibíd.: 5), no es apto para la movilización. Serán estos factores -el no tener la obligación de responder a la llamada a filas, su estancia en Suiza, donde goza de muchas amistades, y el desarrollo de los acontecimientos en los próximos meses- los que apuntalan su decisión de pasar allí el conflicto, algo que será clave para entender su obra de la época.

Suiza, en aquellos momentos, como estado neutral, parece el lugar idóneo desde el que poder abordar con claridad la situación, si bien se palpan las fricciones entre la Suiza alemana y la Suiza francesa, como apunta en su diario el 29 de agosto (1970: 43). Esa Suiza, que, a pesar de ser neutral, aún se fragmenta por las afinidades de cada zona a Alemania y a Francia:

A mi alrededor veo cómo se estremece la Suiza amiga. Su corazón está dividido por la simpatía que siente hacia razas diferentes; se lamenta por no poder elegir libremente entre ellas, por no poder ni tan siquiera expresarlo. Comprendo su tormento; pero es benefactor; y espero que, gracias a él, pueda elevarse por encima de todo y sentir la dicha superior de una armonía de las razas; espero que sea un gran ejemplo para el resto de Europa (Rolland, 2017: 44-45). 
Así, en esos primeros meses, leemos cómo asiste horrorizado a los ataques a Bélgica, a la destrucción de Lovaina y a la nula reacción de la intelectualidad alemana (1970: 32-45), que motivará su célebre Carta abierta a Gerhart Hauptmann en la que expresa que su lucha no es contra los pueblos que pelean entre sí, movidos cuales títeres por intereses superiores -económicos y políticos-, sino contra aquellos que, siendo los más ilustres de cada pueblo -la intelectualidad alemana ${ }^{1}$ en este caso-, apoyan, permiten y fomentan el enfrentamiento; así, los llamará "regimientos de la pluma y del caduceo" (Rolland, 2017: 48).

Por ende, desde su punto de vista, el papel que tienen que desempeñar los intelectuales en esas horas tan terribles es el de despertar conciencias y tratar de frenar con la razón -con todos esos valores europeístas y humanistas que hasta hacía poco defendían- la barbarie que se está produciendo:

Necesitamos los brazos de todos los que no están luchando. A buen seguro los escritores tendrían cosas mejores que hacer que blandir una pluma sanguinaria y, sentados sobre su escritorio, gritar: "¡Mata, mata!". La guerra me resulta odiosa, pero más odiosos me parecen los que cantan sus glorias sin pisar el campo de batalla (Rolland, 2017: 58).

Esa será la lucha -a veces solitaria- que emprenderá a lo largo de todo el conflicto, ayudada, en muchas ocasiones, por los testimonios de los propios soldados que sí que pisan el campo de batalla y rebaten las filfas de la prensa, mendaz y partidista, movida por diversos intereses (Paddock: 2004) ${ }^{2}$. A su vez, si Rolland consigue vertebrar su lucha mediante su voz y la de esos soldados, es porque él tampoco se limita a quedarse sentado detrás de un escritorio a escribir sus diatribas. Bien al

\footnotetext{
${ }^{1}$ En esa carta abierta, publicada en el Journal de Genève, el miércoles 2 de septiembre de 1914 (véase: Rolland, Romain. 2017. Más allá de la contienda y Los precursores. Barcelona: ContraEscritura. Trad. Núria Molines Galarza), aunque carga principalmente contra Gerhart Hauptmann, hace referencia a toda la intelectualidad alemana que, algo más tarde, firmará el "Manifiesto de los 93" (ibíd.: 127-131), un texto en el que noventa y tres intelectuales alemanes (dramaturgos, pintores, científicos, teólogos, historiadores...) defienden la inocencia de Alemania en el conflicto y justifican su actuación. ${ }^{2}$ Véanse, por ejemplo, los artículos de Maurice Barrès en L'Echo de París, quien, por ejemplo, escribe el 19 de diciembre de 1914 en la primera plana de ese medio: "Il n'est plus permis qu'il ait des 'pacifistes'".
} 
contrario, parte de su compromiso con la paz es una acción constante para mitigar los estragos de la guerra.

El compromiso de mayor relevancia para el presente artículo será el que establece con el Comité Internacional de la Cruz Roja (CICR), en Ginebra, específicamente con la Agencia Internacional de Prisioneros de Guerra, que se funda el 21 de agosto de 1914, bajo la presidencia de Gustave Ador (Juin, 2012: 3; Rolland, 2017: 61). La finalidad de esta agencia, con unos trescientos trabajadores voluntarios al mes de su creación, era poner en contacto a los prisioneros de guerra con sus familiares, servir de intermediario en su correspondencia, así como garantizar que les llegase algo de dinero para que pudiesen subsistir (Rolland, 2017: 61) ${ }^{3}$. A su vez, Rolland afirma que su obra no es solo material, sino también moral, ya que con "su conocimiento imparcial de los hechos sucedidos en los países beligerantes, puede contribuir a que el odio exacerbado por relatos fantasiosos desaparezca" (ibíd.: 61). Así, más allá de su aportación práctica como voluntario en la Agencia, como veremos ahora, Rolland aprovechará esos testimonios como "arma" contra el belicismo, el nacionalismo y el odio exacerbado entre los pueblos, azuzado desde la retaguardia sin escuchar a aquellos a quienes se ha enviado a morir por ideales -0 intereses- que poco tienen que ver con su vida.

\section{Testimonios del soldado anónimo: ensayos y artículos}

Odio al militar, no al soldado ${ }^{4}$.

El texto "inaugural" - o, al menos, el que más resonancia tuvo- de toda la serie de artículos y ensayos que Rolland escribió durante la guerra, y que dio nombre a la compilación que se publicó más tarde, fue «Más allá de la contienda» (2017: 34-46). En él ya vemos cómo, desde el inicio, la posición de Rolland hacia el soldado es clara: la juventud de Europa -sin hacer distinciones de bandos ni naciones- está siendo arrojada a una matanza. Entiende lo que los mueve a ir a la batalla, a cumplir con ese deber "heroico" e "histórico" con su pueblo. No se hallan reproches hacia estos jóvenes, que le escriben cartas para hablarle

\footnotetext{
${ }^{3}$ Para una explicación más detallada de las funciones de la Agencia, su funcionamiento y desarrollo, véase su articulo Inter anima caritas, publicado en el Journal de Genève el 30 de octubre de 1914 (Romain Rolland, 2017: 57-66).

${ }^{4}$ Unamuno, Miguel de, "Palabras en homenaje a Romain Rolland" (Rolland, 2017: 17).
} 
del frente y de sus hazañas (Rolland, 2017: 35). Así, no carga las tintas contra el soldado anónimo, que entiende que cumple con su deber, sino contra sus guías morales, políticos, espirituales, pensadores, "maestros de la opinión":

¡Teníais entre las manos tantísimas riquezas vivas, esos tesoros del heroísmo! ¿En qué los habéis gastado? ¿Qué fin le habéis dado a la magnánima entrega de esta juventud que ansiaba sacrificarse? ¡Habéis dejado que se degüellen los unos a los otros! La guerra europea, esta contienda sacrílega que ofrece el lamentable espectáculo de la demente Europa subiendo a la hoguera y desgarrándose las manos como Hércules, ¡eso es lo que habéis logrado! (Rolland, 2017: 36).

Todas las fuerzas del espíritu han sido llamadas a filas y la plaga se extiende por toda Europa, donde el convencimiento de la necesidad, pertinencia y urgencia de la guerra "empujan a millones de hombres a pelear ciegamente, como si fueran hormigas" (ibíd.: 38). Ni el socialismo ni el cristianismo se salvan de contribuir al desastre, Rolland ve en ellos los nacionalistas más encendidos (ibíd: 38-40).

Un texto en el que vemos, por primera vez, cómo Rolland le cede la palabra a los soldados y a los prisioneros de guerra, será Inter anima caritas, publicado en Le Journal de Genève el 30 de octubre de $1914 .{ }^{5}$ En este, habla de cómo, de cada bando, le llegan mensajes alarmados sobre los malos tratos que reciben soldados franceses y alemanes prisioneros, cosa que él trata de desmentir a toda costa mediante los testimonios directos que le llegan a su trabajo como voluntario de la Agencia Internacional de Presos. En una carta a Stefan Zweig del 10 de octubre de 1914, le llega a decir incluso que le han llegado numerosos relatos que hablan de la fraternidad de los soldados franceses con los heridos alemanes (Rolland y Zweig, 2020). Entiende que, en esos momentos, su tarea como intelectual es tratar de desmentir todas las falsas acusaciones que se vierten desde ambos lados para intentar calmar las aguas. Llega a afirmar incluso que les llegan testimonios que hablan de que no se hacen distinciones en el trato que reciben prisioneros y soldados, y que, incluso "se forjan relaciones amistosas entre prisioneros y la Landwehr [milicia]" (Rolland, 2017: 60).

\footnotetext{
${ }^{5}$ El título hace referencia al lema de la Cruz Roja. Texto íntegro en Rolland, 2017:
} 57-66. 
Lejos de caer en el retrato heroico y patriótico, como estamos viendo, el afán de Rolland es mostrar la humanidad de los soldados, demostrar -en la medida de lo posible-, que a ellos no les invade ese odio ciego que ve en los que han orquestado la guerra. Esa es la gran esperanza, que los pueblos, a pesar de todo, no se odien. Vemos un apunte muy interesante cuando Rolland refiere que, por testimonios fiables que le llegan, se ha enterado de que los soldados -de ambos bandos-, confraternando entre ellos, se niegan a ser atendidos por los médicos o a recibir comida antes que sus "camaradas enemigos" (ibíd: 60). Llega a plantearse una interesante reflexión que coloca al soldado como eje "revolucionario-pacifista" del conflicto:

Quién sabe, quizá es en el seno de los propios ejércitos ahí donde el sentimiento de odio nacional es más débil, pues es ahí donde uno aprende a valorar el coraje del adversario, donde tiene que soportar los mismos sufrimientos que el otro y porque, al fin y al cabo, allí donde toda la energía se canaliza hacia la acción puede que ya no quede lugar para el resentimiento. El odio adopta rasgos de dureza implacable en aquellos que no actúan, y algunos intelectuales ofrecen ejemplos atroces al respecto (Íbid: 60).

El soldado, según Rolland, lejos de ser el adalid de los valores nacionalistas, bélicos y patrióticos, podría ser, muy al contrario, el sujeto más empático y "descreído" del relato guerrero. Es fácil odiar desde la retaguardia, alentados por la prensa y las bravatas en los despachos, pero, como apunta Sontag al reflexionar sobre las ideas de Virginia Woolf en Regarding the Pain of Others, cuando no nos conmovemos ante ciertas imágenes de guerra (violentas, brutales, del dolor del otro), nos convertimos en monstruos morales, y sin embargo, aparentemente no lo somos, somos gente de clase educada, pero "our failure is one of imagination, of empathy: we have failed to hold this reality in mind" (2003: 7). El soldado observa esas imágenes sin mediación, sin filtro; las presencia en primera persona, con toda su crudeza, por lo que podemos entender que su capacidad empática sea mayor, ya que entiende ese dolor del otro, que no deja de ser también el suyo.

A su vez -sigue Sontag con Woolf-, esas imágenes que llegan a la retaguardia, a través de la prensa, son las del soldado anónimo, las del otro desconocido, "war is generic, and the images she [Woolf] describes are of anonymous, generic victims" (ibíd: 8). Esa "anonimización" 
del otro, del soldado enemigo, facilita que podamos no empatizar con ese sujeto. Sin embargo, como recoge Rolland, la convivencia entre soldados y soldados prisioneros del otro bando hace que esa distancia, esa anonimización se disuelva: en el momento en el que le ponemos cara y nombre a ese otro, no es tan sencillo desligarnos de lo que nos exige su mirada.

Esa mirada -o esa escritura- no siempre le llega a Rolland desde el bando francés. De hecho, uno de los testimonios más relevantes que recoge en sus artículos de la época lo encontramos en "El asesinato de las élites" (Rolland, 2017: 109-118), donde recupera las cartas de un soldado alemán, con las que pretende desmentir las mentiras que la prensa hace circular sobre el frente y los soldados. En estas cartas, vemos, por ejemplo, cómo este soldado, lejos de cantar las glorias de la guerra y ensañarse con odio contra el enemigo, manifiesta su empatía y compasión hacia el otro bando justo cuando puede mirar al otro a la cara:

Quien está aquí se amolda como puede a la amarga inevitabilidad del sufrimiento y de la muerte [...]. Justo cuando uno debe, como yo, mirar al sufrimiento a la cara, es entonces cuando se estrechan lazos que me unen con aquellos que están allá, al otro lado (y que os unen también con ellos, iqueridos míos! Sí, vosotros también lo sentís, ¿o no?). Si vuelvo de aquí (cosa que ya casi ni espero) el deber que perseguiré con más celo será el de sumergirme en el estudio del pensamiento de aquellos que han sido nuestros enemigos (Ibíd: 114).

En otro testimonio que recoge en este mismo artículo, leemos cómo otro soldado alemán afirma que, lo que desean tanto soldados como oficiales es la paz y que no queda nada del entusiasmo bélico del principio. Lo que más tortura a este soldado alemán es la imagen que le asalta por las noches cuando se sube a lo alto de una colina para contemplar el paisaje en la lejanía: que en otra colina, habrá otro soldado del otro bando sufriendo lo mismo que está sufriendo él (ibíd.: 116-117). De nuevo, el dolor, la desazón y las ganas de que la guerra termine surgen en el mismo seno de la posibilidad de una mirada: la del otro que, a lo lejos, como en un espejo, actúa y sufre como él.

Cabe incidir en la importancia que tiene que Rolland se aventure a recoger los testimonios de soldados alemanes, cosa que, como es de esperar, al igual que por el contenido en favor de la paz del resto de sus artículos, no siempre fue bien recibido (Lemaitre y Lemoine, 2008; 
Roudil, 2013) ${ }^{6}$. De hecho, en previsión a las críticas, en ese mismo artículo se adelanta y responde de manera contundente acerca de la pertenencia de escuchar testimonios de soldados de ambos bandos, sobre todo, porque estos no tienen culpa de las infamias de sus gobiernos:

¿Qué motivos hay para publicar estas páginas? [...] Mi respuesta sería: porque es la verdad y porque esta verdad legítima nuestro juicio, el juicio del universo contra los líderes de Alemania y su política. Lo que han hecho sus ejércitos ya lo sabemos; pero que lo hayan podido hacer con elementos como los que nos encontramos en estas confesiones incrimina todavía más a sus líderes. Desde lo más hondo de los campos de batalla esas voces de una minoría sacrificada se alzan como una condena vengativa contra sus opresores (Rolland, 2017: 117).

Y, del mismo modo que seguirá publicando testimonios de este tipo a lo largo de todo el conflicto, para desactivar con voces de quienes están en primera línea las mentiras de la prensa, los gloriosos relatos del heroísmo guerrero de los soldados -que sirven para que la nación siga soportando más años de guerra y enviando a sus jóvenes a las trincheras-, también plasmará en la literatura estas voces, como veremos a continuación.

\section{De la trinchera a la ficción: el soldado en Clerambault}

Stefan Zweig, en una carta del 23 de diciembre de 1917, le escribe a Rolland: "Estoy convencido de que esta obra será como un monumento a la época" (Rolland y Zweig, 2020). El "monumento" al que se refiere -y que Rolland le pedirá que traduzca al alemán- será Clerambault, historia de una conciencia libre durante la guerra ${ }^{7}$. Esta novela - o confesión, aunque Rolland, irónicamente, advierta que no se puede

\footnotetext{
${ }^{6}$ Uno de los ataques más frontales por su labor pacifista lo podemos ver también en la obra de Loyson (1916), uno de sus enemigos más acérrimos.

${ }^{7}$ La recepción que tuvo esta obra entre otros autores alemanes también fue muy positiva. Véase, por ejemplo, la reseña de Hermann Hesse al respecto en la que dice: "À côté de ses articles qui pendant la guerre ont paru dans le Journal de Genève, ce Clérambault est la profession de foi la plus forte, la plus réfléchie, la plus intime sur la guerre, contre la guerre, contre le manque de spiritualité et de coeur de nos États, de notre politique, de notre presse. Plus que de n'importe lequel de ses autres livres, Rolland pourrait dire que celui-ci, il l'a écrit avec son sang" (Hesse y Rolland, 1972: 69).
} 
considerar autobiográfica (2018: 11)-, si bien se gestó durante los años de guerra, no se publicó hasta años después del final del conflicto, en 1920. Entendemos, por ende, que este ya no es un libro de inmediatez, pensado para actuar durante la guerra, como puedan ser obras tan admiradas por Rolland como Le Feu de Barbusse (1916) -que no deja de ser un testimonio de un soldado en primera persona-, sino un libro para los tiempos de "paz".

En Clerambault, aunque el autor se cuide de recalcar que no es autobiográfico, encontramos claros paralelismos con lo que el propio autor vivió en la época: la acción, que se inicia con la muerte de Jaurès, la protagoniza un escritor burgués, que al principio sí que se ve contagiado del entusiasmo belicista, pero sufre una profunda transformación cuando su hijo muere en el frente. En ese instante, empieza una campaña solitaria en favor de la paz con artículos de prensa, que reciben durísimos ataques por parte de sus colegas escritores, así como de la opinión general.

Curiosamente, el protagonista, Agénor Clerambault, donde encontrará "refugio", o un oído amigo a quien sus palabras sí que dan aliento, será en los soldados, mientras que toda la intelectualidad le da la espalda. Uno de los personajes más destacados entre los soldados que aparecen en la novela es el de Julien Moreau, que una noche se acerca a casa de Clerambault para manifestarle "el bien que le había hecho la lectura de sus artículos" (Rolland, 2018: 171). Así, le confiesa al escritor que, en las trincheras, habían hallado en él una voz que les resultaba cercana. A su vez, este soldado encarna uno de los grandes dramas de los que vuelven a casa -de permiso o heridos-: la incomprensión de la retaguardia, acrecentada por el relato que bebía de la prensa y que nada tenía que ver con lo que experimentaban los soldados en primera línea del frente. Así, Moreau se siente "un extranjero entre ellos, más que entre los salvajes de África” (Rolland, 2018: 172). Lo más terrible para todos ellos es que al volver no encuentran una mirada de comprensión, sino de compasión o de desconcierto, la duda de por qué habían entregado la vida, "la sospecha emponzoñada de que la habían echado a perder para nada" (ibíd.: 173). Clerambault trata de consolarlo, como hará con otros soldados que aparecen más adelante en la novela, pues, recordemos, esta novela es para tiempos de paz, para esos años en los que todos los jóvenes que se han pasado cuatro años en las trincheras regresan al hogar con el tormento de lo vivido y con la triste conciencia 
de saber que ha sido inútil. El escritor le dice al joven Moreau que no ha sido en vano, que de algo tiene que servir; y ese mensaje va para toda una generación de soldados:

Tenéis el cometido más grande que jamás se haya asignado a una generación. Se trata de ver claro, por encima del fuego de las trincheras y de los gases asfixiantes con los que os ciegan, al igual que al enemigo, los alborotadores de la retaguardia. Yo no bendigo el sufrimiento. ¡Dejemos esa aberración a los devotos de esas viejas religiones! Nosotros no amamos el dolor, queremos la alegría, pero cuando vienen las aflicciones, ¡al menos que nos sirvan! ¡Que esto que vosotros padecéis no lo padezcan otros! (Ibíd.: 174).

El joven Moreau, ante el aliento de sus palabras, le presentará más adelante a otros compañeros de su misma generación, con los que Clerambault empezará a reunirse periódicamente. En estas reuniones, Rolland aprovecha para retratar las diferentes visiones que tienen los soldados ante el conflicto a través de la ficción -pudo ver muchas de estas posturas en las cartas que pasaban por sus manos en la Agencia Internacional de Presos, así como en las cartas recibía personalmente de soldados ${ }^{8}$. Esos grupos de jóvenes estaban formados por imbeles y por aquellos que habían sido relevados de servicio.

En ellos, Clerambault encuentra dos grandes grupos: los que consideran que leen en sus textos una confirmación de lo que ellos mismos piensan y los que, ya con la revolución en las venas y hartos de la impotencia de la retaguardia, desean actuar y pretenden convencer al anciano burgués para que los apoye. Entre ellos, destaca la voz de Gillot, un joven soldado que quedó destrozado por un obús, que suele discutir con Moreau, al tener una manera diferente de entender lo que les está sucediendo. Este afirma que lo peor que les sucede es la "indiferencia" (Rolland, 2018: 183) - esa incapacidad de empatizar ante la mirada del otro, ante el dolor ajeno-; el verdadero problema que subyace, según Gillot, es que no hay amor por la vida:

\footnotetext{
${ }^{8}$ Véase, por ejemplo, una carta del 5 de octubre de 1915 que transcribe en su diario, de un soldado alemán, Minnecke, en la que este joven le pide que no abandone su labor ya que él es libre, mientras que, en la trinchera, tienen las manos atadas (Rolland, 1970: 549-551).
} 
Desde que somos pequeños, se nos canta la muerte, la belleza de la muerte o de los que están muertos. La historia, el catecismo, "Morir por la patria". O bien el clero, o bien los patriotas; y después, la vida nos molesta. Se diría que se las arreglan para que la vida de hoy resulte lo más molesta posible (Ibíd.: 184).

Gillot afirma que el cambio radical que vivió en las trincheras - de la indiferencia ante la muerte- se produjo justo cuando estuvo a punto de morir: en ese momento se dio realmente cuenta de lo valiosa que era la vida, que incluso la imagen del proyectil que a los pocos instantes iba a impactar a su lado era bella (ibíd.: 185).

Estos jóvenes como Moreau y como Gillot -entre otros-, le sirven también a Rolland para plantear cómo nace el germen revolucionario entre los soldados y los jóvenes, ese nuevo ídolo en ciernes: la Dictadura del Proletariado. Estos defienden que será la manera "definitiva" de acabar con todos sus males, con quienes los han llevado a las trincheras y habían apoyado la guerra. Clerambault rebate sus argumentos con más ideas pacifistas que son, al fin y al cabo, todo lo que guía su obra en este periodo: "Siempre la guerra en aras del Derecho y la Libertad; siempre la última guerra que debe acabar con la guerra" (ibíd.: 190). Les pide así valentía, que, del mismo modo que han conseguido ver que el enemigo estaba en todas partes -en casa y en la del enemigo-, no caigan en absolutos y vuelvan a cegarse, suplantando una opresión por otra.

Así, hemos visto que, en el caso de su obra de ficción, las diferentes representaciones del soldado que encontramos le sirven a Rolland como interlocutores ficticios - por boca de Agénor Clerambault-ante el debate que se abre al final de la guerra y en esos primeros años de paz, inestable y tambaleante, que vendrán por delante.

\section{Conclusiones}

Como hemos podido ver sus obras del período bélico -tanto en los artículos recogidos en Más allá de la contienda como en Clerambault-, la figura del soldado anónimo cobra un papel protagonista en la lucha por la paz de Romain Rolland. Dándoles voz directamente, al transcribir sus cartas y testimonios en los artículos que publica, como bajo el manto de la ficción, Rolland entiende que el soldado es un sujeto 
"revolucionario" que puede minar las convicciones que la prensa, desde la retaguardia, pretende apuntalar, interesada en difundir relatos gloriosos sobre el conflicto.

Lo que nos demuestran esos testimonios de los soldados es que, cuando se ven confrontados con la mirada del otro, con el dolor del igual -aunque enemigo-, pueden surgir lazos de empatía que desactivan el relato belicista que los empuja a seguir adelante convencidos de la causa. Siguen ahí, más por obligación que por convicción, deseando que llegue la paz. Y, sin embargo, cuando vuelven, la mirada que encuentran no es, en muchos casos, más acogedora que las trincheras. El relato que los poderes han incrustado en el imaginario colectivo de la sociedad no permite que quienes no han estado allí, presenciando lo que sucedía en el frente, puedan comprender el dolor que traen los que regresan, el antibelicismo, el desengaño hacia la causa, sus ansias de paz.

Así, cabe decir que el gran valor de la obra de Rolland de la época, de su idealismo -que le valió un Nobel-, más allá de llegar a frenar el conflicto, sirve, en muchos casos, de bálsamo para quienes vuelven, para quienes quieren desertar o han perdido la fe en la "santa" causa de la lucha por la patria; Clerambault, en 1920, es una obra para los tiempos de paz y sus artículos y ensayos, aunque publicados en tiempos de guerra, vemos que sirvieron más a quienes estaban en las trincheras y encontraron en ellos una "voz amiga" que a quienes realmente iban dirigidos, los intelectuales que apoyaron con sus textos el conflicto bélico que desgarró Europa.

\section{Bibliografía}

Barbusse, Henri. 1916. Le Feu (Journal d'une escouade). París: E. Flammarion.

Corbellari, Alain (ed.). 2012. Romain Rolland et la Suisse. Lausana: Études de Lettres.

Duchatelet, Bernard. 1973. La genèse de Jean-Christophe. I: La préparation (1886-1903). Annales de Bretagne 80(3-4): 573-59. doi: https://doi. org/10.3406/abpo.1973.2703

Hesse, Hermann y Romain, Rolland. 1972. D'une rive à l'autre, correspondance, fragments du journal et textes diverses. París: Albin Michel.

Juin, Guillaume. 2012. Romain Rolland dans le contexte suisse de la Grande Guerre. Etudes de lettres 3: 75-104. 
Lemaitre, Martine y Lemoine, Roland. 2008. Romain Rolland, les pacifistes, leurs détracteurs: amour et haine pendant la Grande Guerre (cat. exp.). Clamecy: Études Rollandiennes, 23.

Loyson, Paul H. 1916. Êtes-vous neutres devant le crime? París: Berger-Levrault.

Paddock, Troy. R. E. (ed.). 2004. A Call to Arms: Propaganda, Public Opinion, and Newspapers in the Great War. Londres: Praege.

Rolland, Romain \& Zweig, Stefan. 2020. Correspondencia 1910-1918. De un mundo a otro mundo. Barcelona: Acantilado (en prensa). Trad. y ed. Núria Molines Galarza y José Aníbal Campos.

Rolland, Romain. 2018. Clerambault. Barcelona: ContraEscritura. Trad. y ed. Núria Molines Galarza.

Rolland, Romain. 2017. Más allá de la contienda y Los precursores. Barcelona: ContraEscritura. Trad. Núria Molines Galarza.

Rolland, Romain. 2007. Jean Christophe. París: Albin Michel.

Rolland, Romain. 1970. Journal des années de guerre, 1914-1919: notes et documents pour servir à l'histoire morale de l'Europe de ce temps. París: Albin Michel.

Roudil, Roland. 2013. Au-dessus de la Mêlée, histoire d'une édition (sept.1914nov.1915). Cahiers de Brèves 31(1): 6-12.

Sontag, Susan. 2003. Regarding the Pain of Others. Londres: Penguin.

Zweig, Stefan. 2001. El mundo de ayer. Barcelona: Acantilado. Trad. Agata Orzeszek y Joan Fontcuberta.

Zweig, Stefan. 1942. Romain Rolland, el hombre y su obra. Buenos Aires: Claridad. Trad. Alfredo Cahn. 
